Canadian Studies in Population, Vol. 37.3-4, Fall/Winter, pp. 611-612

\title{
Trilingual Glossary of Demographic Terminology: English-Japanese-German/Japanese-English-German German-Japanese-English
}

\author{
Koch, Matthias, Claus Harmer and Florian Coulmas \\ Brill: Leiden and Boston, 2007 \\ ISBN 978-90-04-15476-6 \\ U.S. \$231.00, 926 pages \\ Reviewed by \\ Roderic Beaujot and Alain Gagnon \\ University of Western Ontario \\ London, Ontario, Canada
}

This is a glossary of over 7,500 terms, placed into three sections, one section gives the English terms along with the Japanese and German translations, the next section gives the Japanese terms with their English and German translations, then there are the German terms with their Japanese and English translations.

The glossary contains not only terms from demography and population, including social demography, population geography, political demography, economic demography, historical demography, medical demography, biodemography, mathematical demography, but also relevant terms from the adjacent disciplines of psychology, law, technology, religion, linguistics and education.

This is a glossary, and not a dictionary. Thus it takes a rather different approach compared to the Multilingual Demographic Dictionary (English editions published in 1958 by the United Nations, Department of Economic and Social Affairs, as Population Studies, No. 29, and in 1982 by the International Union for the Scientific Study of Population, Ordina Editions). That is, the UN/IUSSP volume has a glossary of terms, indexed through a numbering system that places these terms in a definitional context. The same numbering system is used a separate volume for each language. In contrast, the present volume has a glossary of terms with limited definitional context, but all in the same volume.

While the UN/IUSSP dictionary has no entry for "gender" nor "reproductive rights" both of these are included in the glossary, in fact there are also the terms "gender empowerment measure," "gender gap," "gender identify," "gender identity-disorder," "gender imbalance," "gender mainstreaming," "gender pay gap," "gender ratio," "gender roles," "gender theory," "gender-equal society," "gender-free," "gender-related development index," "genderisation," and "genderisation of labour."

CSP 2010, 37.3-4: 611-612 
In the English-Japanese-German section of the glossary, these terms do not receive any further definitions in English. However, the translation in the other languages can be quite extensive. The term "gender pay gap" lays the foundation for the following terms: "geschlechtsspezifische; Einkommensunterschiede/Entgeltdifferenz; genchlechtsspezifisches Lohngefalle; Lohndiskriminierung von Frauen; unterschiedliche Bezahlung von Frauenund Mannerarbeit." This expression translates into English as the differences in salary; gender-specific decrease in salary; gender discrimination in salary (for women); different salaries (traditionally) associated with women and men's tasks or types of jobs, for example: policemen get higher salaries than nurses. The Japanese text for "gender pay gap" is equally long. In contrast, the term "gene" generates only the term "Gen" in German.

To choose another term, "aging" receives three references in the IUSSP dictionary, but there are 58 terms in the glossary, from "ageing clock" to "ageing, theory of successful" and "ageing, wear-and-tear theory of." In contrast, the term "agnostic" has an entry in the IUSSP dictionary, with the suggested synonyms of "freethinkers" or "atheists" under the general term of "religious statistics" but the glossary only has the terms "religion" and "religious minority," with no entry for "agnostic" nor "atheist."

While we have preference for the UN/IUSSP approach that provides definitions in addition to the translation of terms, this Trilingual Glossary of Demographic Terminology serves a very useful purpose. As the preface indicates the glossary is an important research tool through the translations of such a rich array of terms into three languages. Persons working in the field of demography will come to appreciate the variety of concepts that can be associated with their discipline, while persons from other disciplines will have an easy reference to the accepted terms used in population studies. 